\title{
AUTOMATIC CLASSIFICATION USING IMAGE PROCESSING TECHNIQUE IN MATLAB FOR ORANGE FRUITS
}

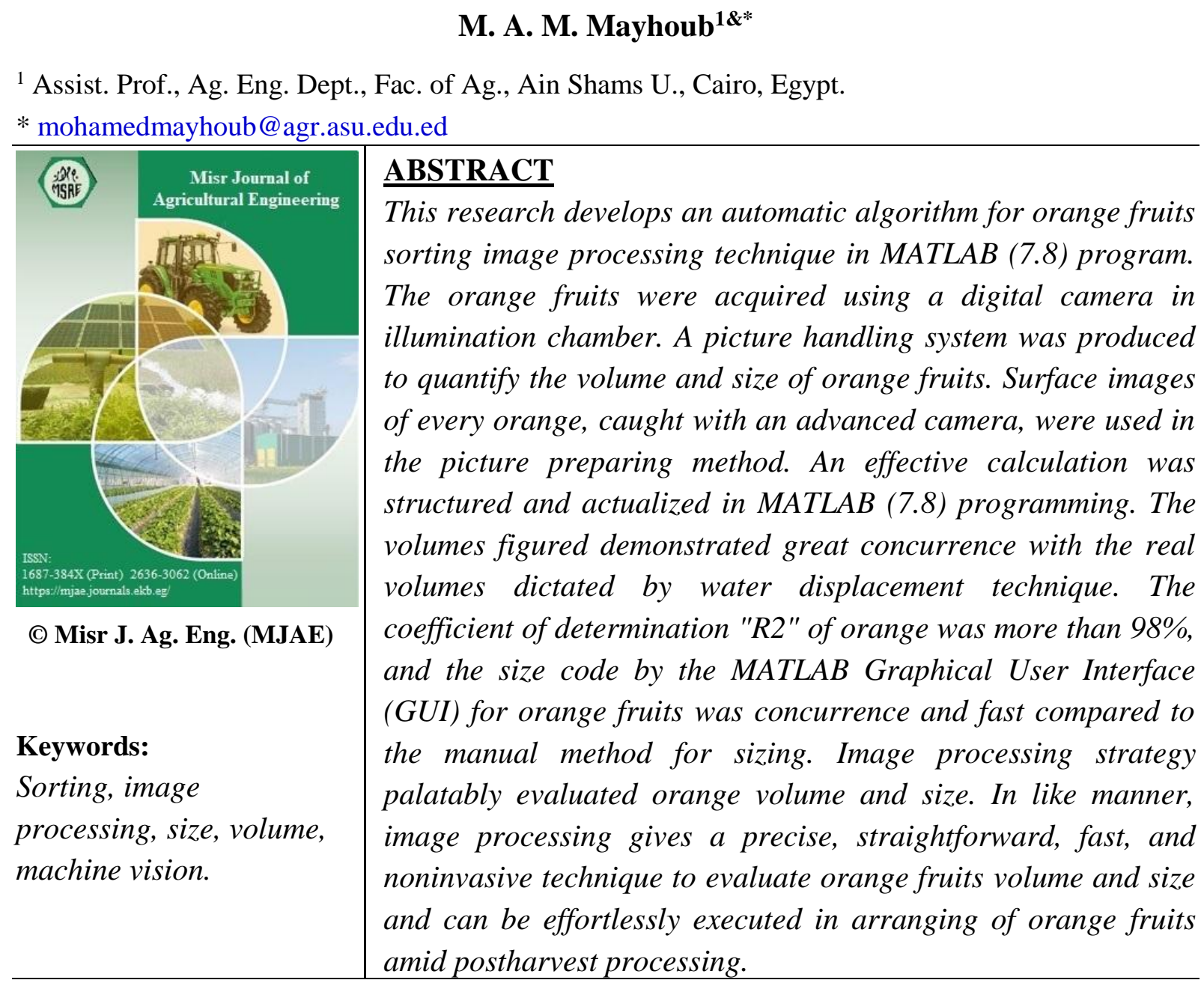

\section{INTRODUCTION}

$\mathrm{F}$ or the most part, the regularly expanding populace, misfortunes engaged with preparing and the expanding demand of products of high caliber with great appearance, there is a requirement for the advancement of exact, quick, and centered quality assurance of sustenance and horticultural items like fruits and vegetables.

Since, evaluating basically done by experiencing specialists who work along the transport frameworks, certain work - related issues, including rising work costs, generation squander on account of conflicting arranging and grading and human mistakes, are tormenting the potatobundling industry (Zhou et al. 1998). Other than the inconsistency and subjectivity, the manual procedure is extremely repetitive, difficult, exorbitant, and is effectively influenced by encompassing conditions (Razmjooy et al. 2012).

Arranging of rural items is proficient dependent on appearance (shading and nonattendance defects), surface, shape, and sizes. Manual arranging depends on conventional visual quality inspection performed by human administrators, which is dull, tedious, moderate, and nonconsistent. It has turned out to be progressively hard to contract ability that is satisfactorily prepared and willing to embrace the monotonous assignment of examination. These reasons make the product quality not adjusting to particulars and quality guidelines set for the 
agricultural items per the prerequisites of the global market on account of export. A savvy, reliable, predominant speed, meeting quality models and precise sorting can be accomplished with machine vision and picture handling strategy in arranging and grading tasks of horticultural items. Picture preparing is the utilization of a PC to analyze an image with the end goal to extricate significant data good and gone. Utilizing this powerful device, precise data, for example, the pictures shape, volume, size, or appearance, can be gotten from a question that could not be effortlessly acquired by human perception.

The most important parameter in adjustment, transportation, delivering, and packaging systems is physical properties of farming items. Among these physical properties, volumes, mass, surface area and center of gravity are their most critical in valuing systems. The major physical properties of citrus natural products are shape, size, density, porosity, volume, and mass of foods grown from the ground against different surfaces (Akar and Aydin, 2005). These properties have been considered for different horticultural items, for example, breadfruit, natural products, onion, almond, escapade, myrtle, orange and pomegranate (Omobuwajo et al. 1999; Aydin and Ozcan, 2002; Abhayawick et al. 2002; Aydin, 2003; Sessiz et al. 2007; Aydine and Ozcan, 2007; Hassan, 2002 and Khoshnam et al. 2007). The span of foods grown from the ground is essential physiological property that can be portrayed by various parameters, for example, volume, weight, length, and distance across (Moreda et al. 2009).

In the rural division, the effectiveness and the precise evaluating process is exceptionally basic to expand the efficiency of create. Ordinary brilliant natural products are traded to different nations and create a decent salary. That is the reason for evaluating procedure of the natural product is critical to enhance the nature of fruits (Ge, et al. 2007; and Sadegaonkar and Wagh, 2015).

The goal of this examination is to build up a picture handling strategy for determination of orange size and volume using MATLAB Graphical User Interface (GUI) that are essential for planning an extraordinary machine or analyzing the subsequent conduct in transporting items.

\section{MATERIALS AND METHODS}

\section{Image acquisition}

The picture catch chamber utilized in this investigation appeared in Figure $\mathbf{1}$ was based on that exhibited by Kang et al. (2008). The internal size of the light box is $70 \times 70 \times 50 \mathrm{~cm}$. Two fluorescence lights (TL-D Select, 18W/965, Philips) were attached at the top corner of the light box, in parallel, at an edge of $45 \circ$ to the item area Papadakis el.al. (2000). The two lights were secured with diffuse secures. This light box is intended to enlighten an A3 measure area. With the end goal to enlighten this vast surface as equally as would be prudent, within walls and roof were painted white, while the floor (background for the photographs) was painted dark to anticipate reflection. A digital camera (Samsung ST65) capture pictures through a gap on the top surface. The camera settings for this test were: manual mode ISO200; without using zoom and flash; resolution $14 \mathrm{MP}$; format JPEG.

Approach including assurance of orange fruits volume and size by picture handling method incorporates picture securing errand according to (Eissa, et. al.,2012), assurance of relationship recipe, picture processing undertaking. These means are additionally explained in the accompanying sub-segments. Figure 2 summarizes the methodology involved. 


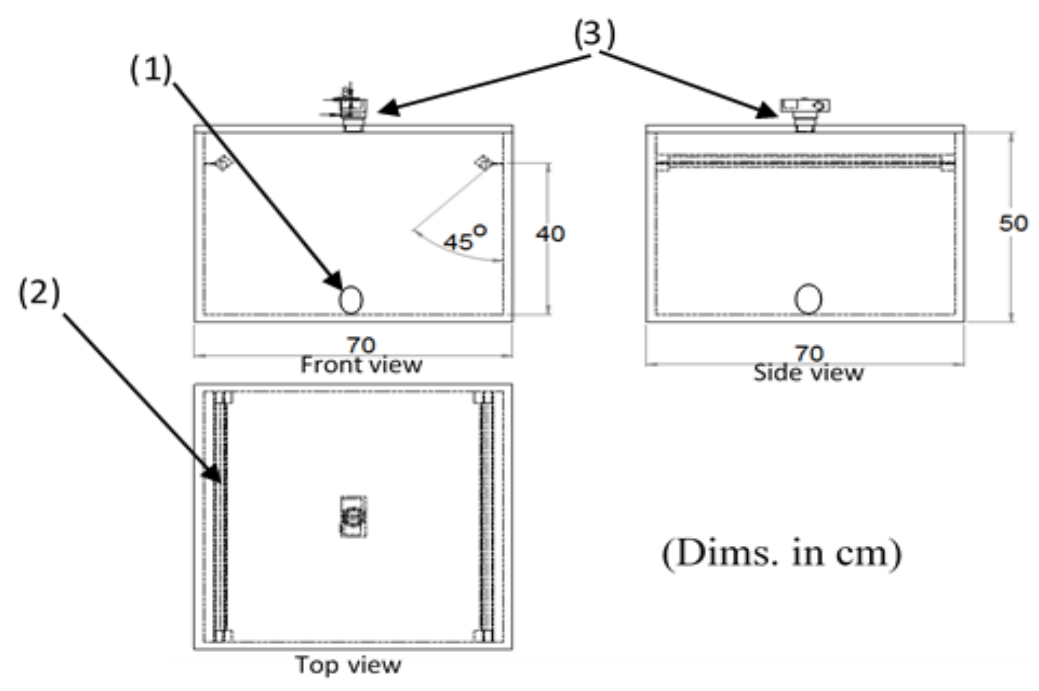

Figure 1: Capturing champer views. Where 1) Orange fruit sample, 2) Philips, TL-D Delux, 18W/965 Fluorescent lamp, 3) Digital camera.

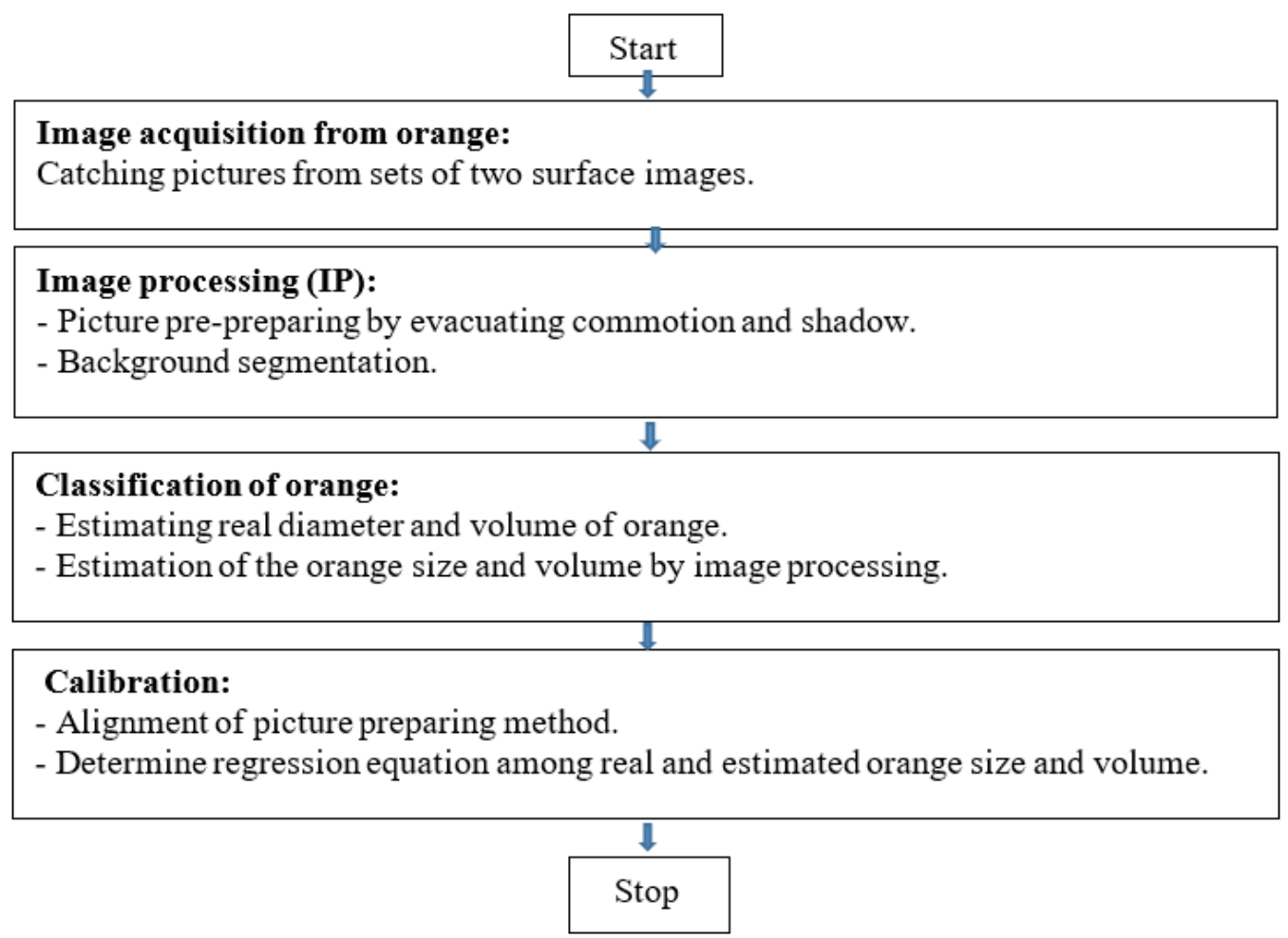

Figure 2: Methodology adapted in this research

\section{Image processing}

A PC program, written in MATLAB 7.8, was created for handling, and investigating the caught pictures. The program naturally records the surface pictures of the example fruits.

\section{Image pre-processing:}

In this progression the shading picture is changed over to a grayscale picture, called the power image. To lessen the computational time of handling the pictures were sub-sampled to $818 * 527$ pixels.

\section{Segmentation}

The division procedure included the accompanying advances: (1) change of shading picture to grey-scale esteems; (2) utilization of an edge and foundation subtraction to acquire the binary 
picture; (3) shutting the little loud openings inside the object; and (4) covering the shape of the twofold picture to the first shading image, as follow recommended by Naik and Patel 2017.

\section{Classification of orange fruit:}

Fruits samples: 39 oranges samples were utilization of Washington navel orange assortment amid test periods. Tests were given in various sizes. Organic products were chosen for opportunity from defects via watchful visual investigation, exchanged to the research facility to utilize. the example of orange was chosen haphazardly from the field of Daltex Organization situated at El-Beheira Governorate - Egypt for evaluation.

\section{Measuring actual diameter and volume of fruit}

The real diameter for orange samples was determined by caliber $(0.01 \mathrm{~mm}$ accuracy). And the genuine volume of natural products can be estimated by water displacement method (WDM). The WDM is a standout amongst the most well-known and straightforward methods for estimating the volume of expansive objects, for example, fruit and vegetables (Mohsenin, 1986)

$$
\operatorname{volume}\left(\mathrm{cm}^{3}\right)=\frac{\text { Weight of displaced water }(\mathrm{kg})}{\text { Water density }\left(\frac{\mathrm{kg}}{\mathrm{cm}^{3}}\right)}
$$

\section{Estimation and calibrating orange volume}

To obtain an index of measuring image processing method (IPM), two images were chosen and after doing pre-processing section, the binary image was obtained. Then, the area of section that was separated had obtained by pixel from this image. Regards that the superficial shape of orange was like spherical body, samples were regarded as sphere. As clear, the volume of sphere is given by $\left(\mathbf{V}=\mathbf{4} / \mathbf{3} \pi \mathbf{r}^{\mathbf{3}}\right)$, by obtaining the area of Figure 3 (Part c) and that two-dimensional image of sphere is the biggest of its Circumferential circle and its radius is the same as radius of sphere. Therefore, by using obtained area of Circle from image processing method, the radius (r) by pixel from relation $\left(A=\pi r^{2}\right)$. As Indicated, to calibrate, it was used of two images of orange samples obtained from mean samples chosen randomly. Calibrating was that the ratio of the real volume from water displacement method, and the volume by pixel from image processing method was calculated. This ratio was used to convert the volume by pixel of other samples of orange and their volume was obtained by $\mathrm{cm} 3$, according to Fellegari and Navid (2011).

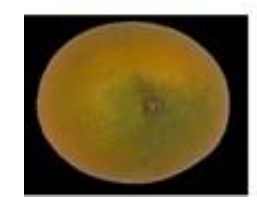

(a)

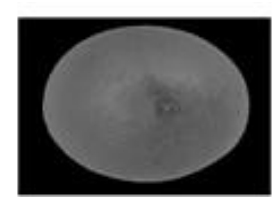

(b)

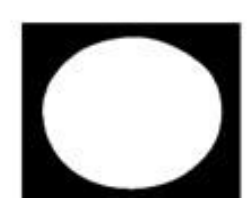

(c)

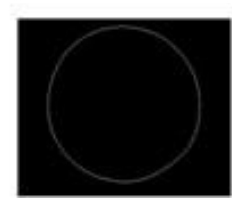

(d)

Figure 3: (a) Original RGB color, (b) grayscale, (c) black-and-white and (d) outline images of orange.

The images were converted to gray scale images then the binary images were obtained using a random threshold and the holes of oranges in images were constructed. Then images were labeled. Finally, determination of the orange fruit size and volume of the imaging were performed at Graphical User Interface (GUI) that created in MATLAB 7.8 using image processing toolbox (MATLAB 2009) as shown in Figure 4. 


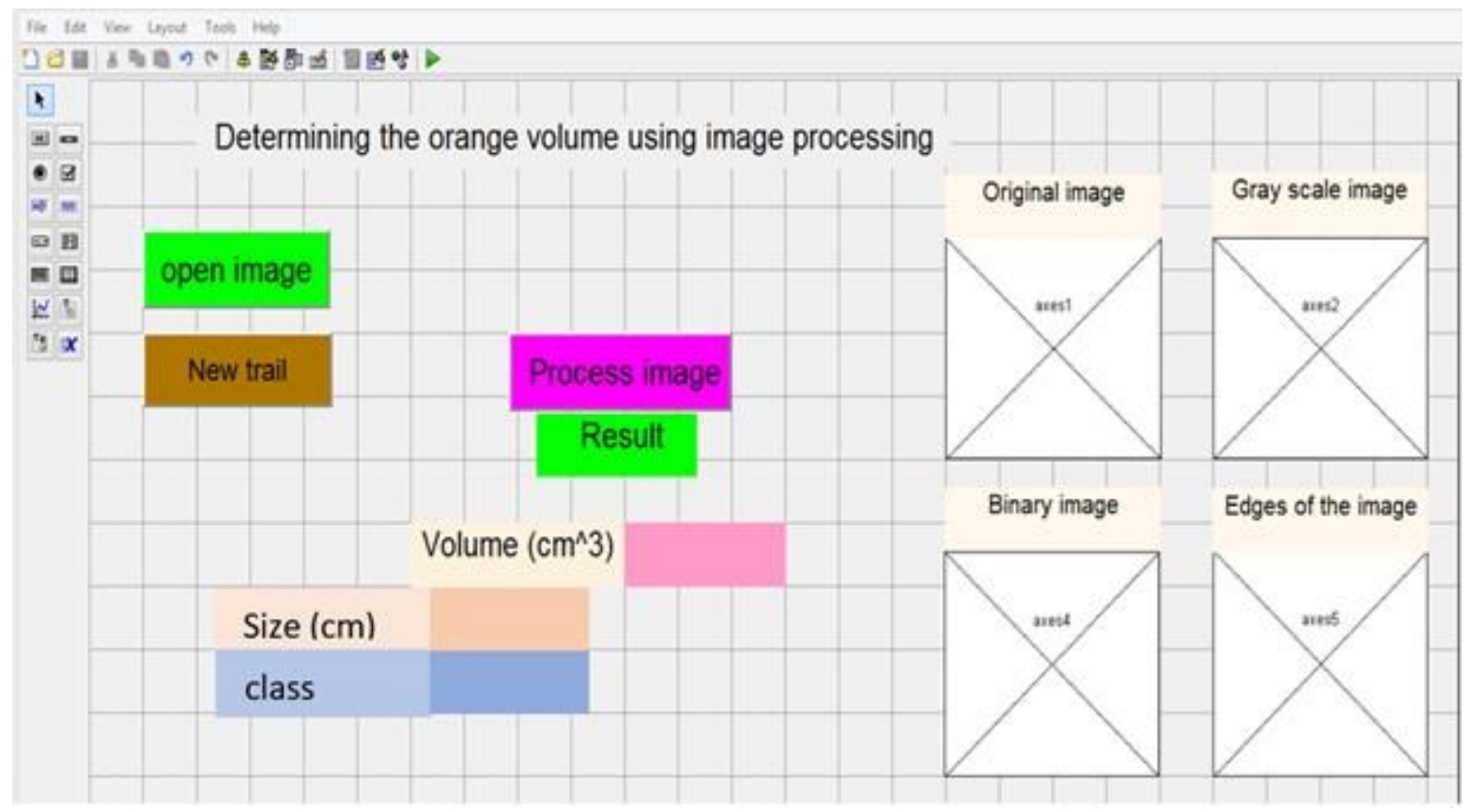

Figure 4: Graphical User Interface (GUI) layout

\section{Approximation of the orange size by IP.}

Size is determined maximum diameter of fruit equatorial section, in accordance as in Table (1).

Table (1): The size code by diameter according to (European Commission, 2011 and Codex Alimentarius, 2005).

\begin{tabular}{l|l}
\hline Size Code & Diameter $(\mathbf{m m})$ \\
\hline 0 & $92-110$ \\
\hline 1 & $87-100$ \\
\hline 2 & $84-96$ \\
\hline 3 & $81-92$ \\
\hline 4 & $77-88$ \\
\hline 5 & $73-84$ \\
\hline 6 & $70-80$ \\
\hline 7 & $67-76$ \\
\hline 8 & $64-73$ \\
\hline 9 & $62-70$ \\
\hline 10 & $60-68$ \\
\hline 11 & $58-66$ \\
\hline 12 & $56-63$ \\
\hline 13 & $53-60$ \\
\hline
\end{tabular}

\section{RESULTS AND DISCUSSION}

\section{Estimation of orange volume image processing}

In this research a demo was developed by using MATLAB (7.8) software to extract the final orange images and processing and then the volume and size code were determined. 
The figure (5) represents the volume and size of orange under clicked the process image button. From the observation based on figure, the surface of captured image is converting to gray image then convert to binary image to determine the orange fruit volume and size.

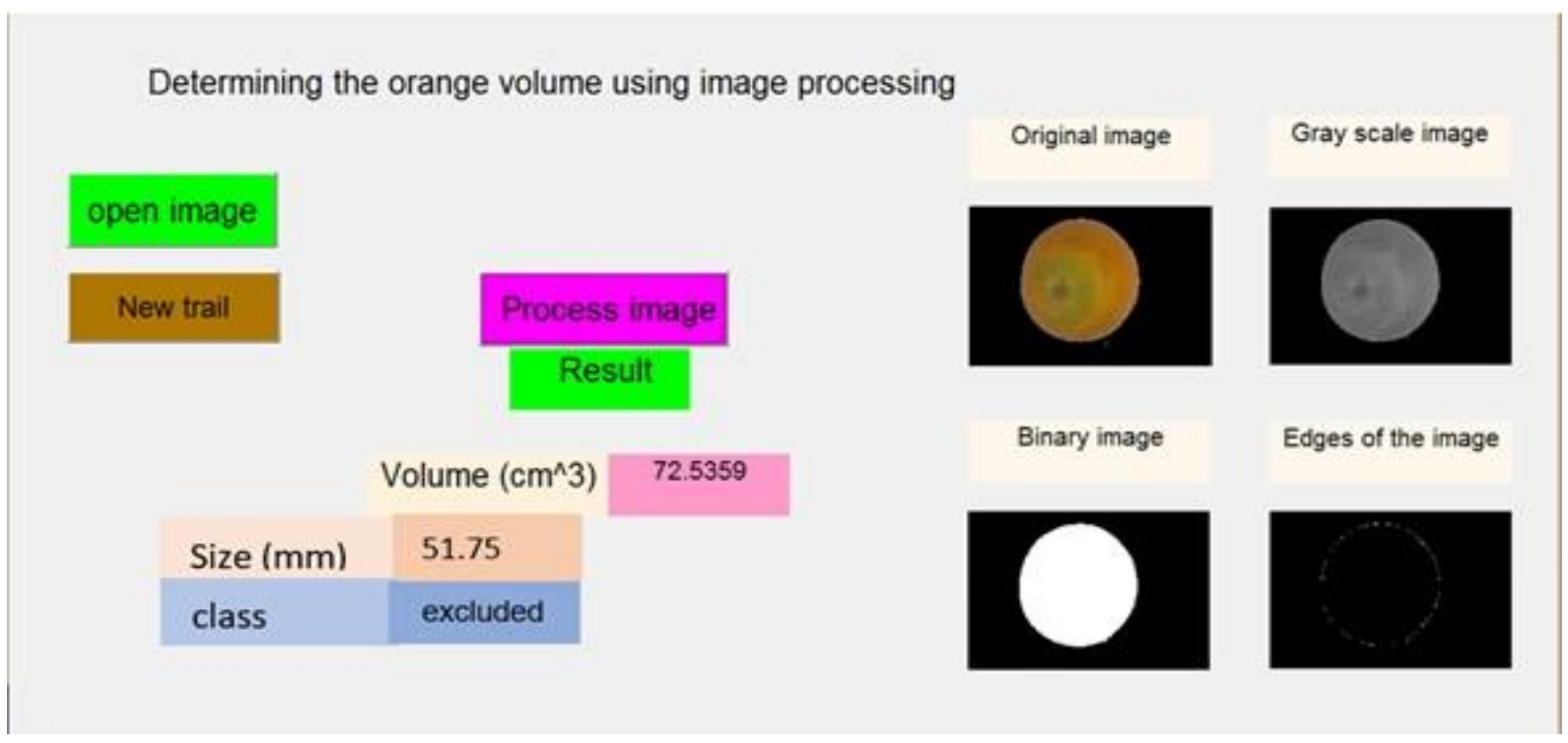

Figure (5): Determining the orange volume and size using image processing (GUI)

\section{Orange calibration results}

The volume of twelve being used samples were calculated by WDM and everyone were obtained by relation sphere volume (r). Also, (r) was calculated in image processing method (IPM) using area. Finally, ratio (r) calculated from WDM volume to (r) calculated from IPM was cleared for every sample. Then mean of both ratios was considered for all samples as calibration ratio. This ratio was equal to 0.261 . Results from image processing method that converted to sample volumes using ratio in calibration, it has obtained along volume data calculated from base WMD in Table (2).

\section{Comparison of image processing method with actual method}

The results of comparison between predicted (IP) and actual (WDM) volumes of orange fruits are shown in Figure (6). The correlation coefficient $\left(\mathrm{R}^{2}\right)$ for orange was more than 0.98 . The $\mathrm{R}^{2}$ values can be interpreted as the proportion of the variance in the IP estimates attributable to the variance in the actual measurements. The higher value of $\mathrm{R}^{2}$, it means the IP results are closer to the actual (WDM) results. The proposed IP method yielded above $98 \%$ accuracy in estimating orange fruit volume, So IP method can be used in estimating orange fruit volume.

The results of comparison between predicted (IP) and actual diameter of orange fruits are shown in Figure (7). The correlation coefficient $\left(\mathrm{R}^{2}\right)$ for orange was 0.99 . The $\mathrm{R}^{2}$ values can be interpreted as the proportion of the variance in the IP estimates attributable to the variance in the actual measurements. The higher value of $\mathrm{R}^{2}$, it means the IP results are closer to the actual results. Figure (8) illustrate the determining the size of orange fruits by measuring the diameter by image processing (IP) and caliper methods, this groups from size by marketing standards (European Commission, 2011 and Codex Alimentarius, 2005), the results showed that the size categories were closely via using the two methods. 
Table (2): Volumes and size obtained from both methods for all samples studied.

\begin{tabular}{|c|c|c|c|c|c|}
\hline & \multicolumn{3}{|c|}{ Size (diameter) (mm) } & \multicolumn{2}{|c|}{ Volumes $\left(\mathrm{cm}^{3}\right)$} \\
\hline & $\begin{array}{l}\text { Average dia. } \\
\text { (pixel) }\end{array}$ & $\begin{array}{r}\text { Dia. } \\
(\mathrm{mm}) \mathrm{IP}\end{array}$ & $\begin{array}{l}\text { Dia. }(\mathrm{mm}) \\
\text { caliper }\end{array}$ & WDM & IPM \\
\hline 1 & 136.42 & 35.57 & 36.22 & 22.10 & 23.54 \\
\hline 2 & 139.42 & 36.35 & 36.89 & 25.47 & 25.13 \\
\hline 3 & 142.26 & 37.09 & 38.88 & 21.80 & 26.69 \\
\hline 4 & 147.39 & 38.42 & 38.00 & 39.42 & 29.69 \\
\hline 5 & 152.46 & 39.75 & 38.77 & 42.17 & 32.86 \\
\hline 6 & 153.65 & 40.06 & 38.65 & 36.84 & 33.63 \\
\hline 7 & 153.74 & 40.08 & 41.68 & 40.89 & 33.69 \\
\hline 8 & 172.49 & 44.97 & 45.54 & 57.92 & 47.59 \\
\hline 9 & 182.45 & 47.56 & 46.15 & 66.48 & 56.31 \\
\hline 10 & 182.45 & 47.56 & 46.85 & 58.48 & 56.31 \\
\hline 11 & 187.89 & 48.98 & 50.49 & 62.97 & 61.50 \\
\hline 12 & 197.75 & 51.55 & 52.24 & 71.81 & 71.70 \\
\hline 13 & 209.05 & 54.50 & 56.61 & 95.07 & 84.71 \\
\hline 14 & 210.94 & 54.99 & 55.67 & 97.08 & 87.03 \\
\hline 15 & 212.90 & 55.50 & 54.67 & 87.20 & 89.48 \\
\hline 16 & 219.34 & 57.18 & 57.85 & 87.45 & 97.85 \\
\hline 17 & 223.83 & 58.35 & 59.46 & 105.76 & 103.98 \\
\hline 18 & 225.12 & 58.69 & 58.83 & 95.33 & 105.79 \\
\hline 19 & 228.55 & 59.58 & 57.95 & 100.57 & 110.69 \\
\hline 20 & 230.36 & 60.06 & 61.32 & 100.88 & 113.36 \\
\hline 21 & 230.95 & 60.21 & 61.44 & 107.63 & 114.23 \\
\hline 22 & 235.35 & 61.36 & 62.43 & 114.40 & 120.88 \\
\hline 23 & 239.78 & 62.51 & 61.85 & 140.41 & 127.83 \\
\hline 24 & 240.56 & 62.71 & 62.30 & 145.50 & 129.08 \\
\hline 25 & 247.07 & 64.41 & 65.72 & 148.82 & 139.85 \\
\hline 26 & 257.41 & 67.11 & 66.21 & 150.68 & 158.16 \\
\hline 27 & 260.72 & 67.97 & 68.75 & 154.03 & 164.34 \\
\hline 28 & 262.32 & 68.39 & 66.93 & 152.66 & 167.38 \\
\hline 29 & 264.20 & 68.88 & 69.48 & 184.80 & 171.00 \\
\hline 30 & 268.37 & 69.97 & 71.11 & 174.93 & 179.24 \\
\hline 31 & 287.20 & 74.87 & 73.36 & 237.94 & 219.66 \\
\hline 32 & 287.20 & 74.87 & 75.44 & 210.94 & 219.66 \\
\hline 33 & 289.49 & 75.47 & 74.67 & 235.52 & 224.96 \\
\hline 34 & 289.83 & 75.56 & 75.70 & 250.21 & 225.74 \\
\hline 35 & 301.00 & 78.47 & 77.84 & 225.71 & 252.88 \\
\hline 36 & 317.04 & 82.65 & 81.32 & 270.60 & 295.48 \\
\hline 37 & 318.99 & 83.16 & 82.11 & 288.35 & 300.97 \\
\hline 38 & 321.94 & 83.93 & 82.55 & 325.67 & 309.42 \\
\hline 39 & 354.11 & 92.32 & 91.22 & 420.28 & 411.74 \\
\hline Mean & 230.31 & 60.04 & 60.08 & 134.74 & 133.95 \\
\hline
\end{tabular}


Anyway, in addition IPM to calculate size and volume of orange fruit is not only fast, no harmful, and care ness way, but can obtain the size and volume and size code of many samples simultaneous. Also, this way can be employed in systems after harvesting such as ones which make grouping by sizing and can add separating by diameter and volume to this system to be economic. Other than this, image processing method to identify size and volume, can be even useful pre-harvest processes.

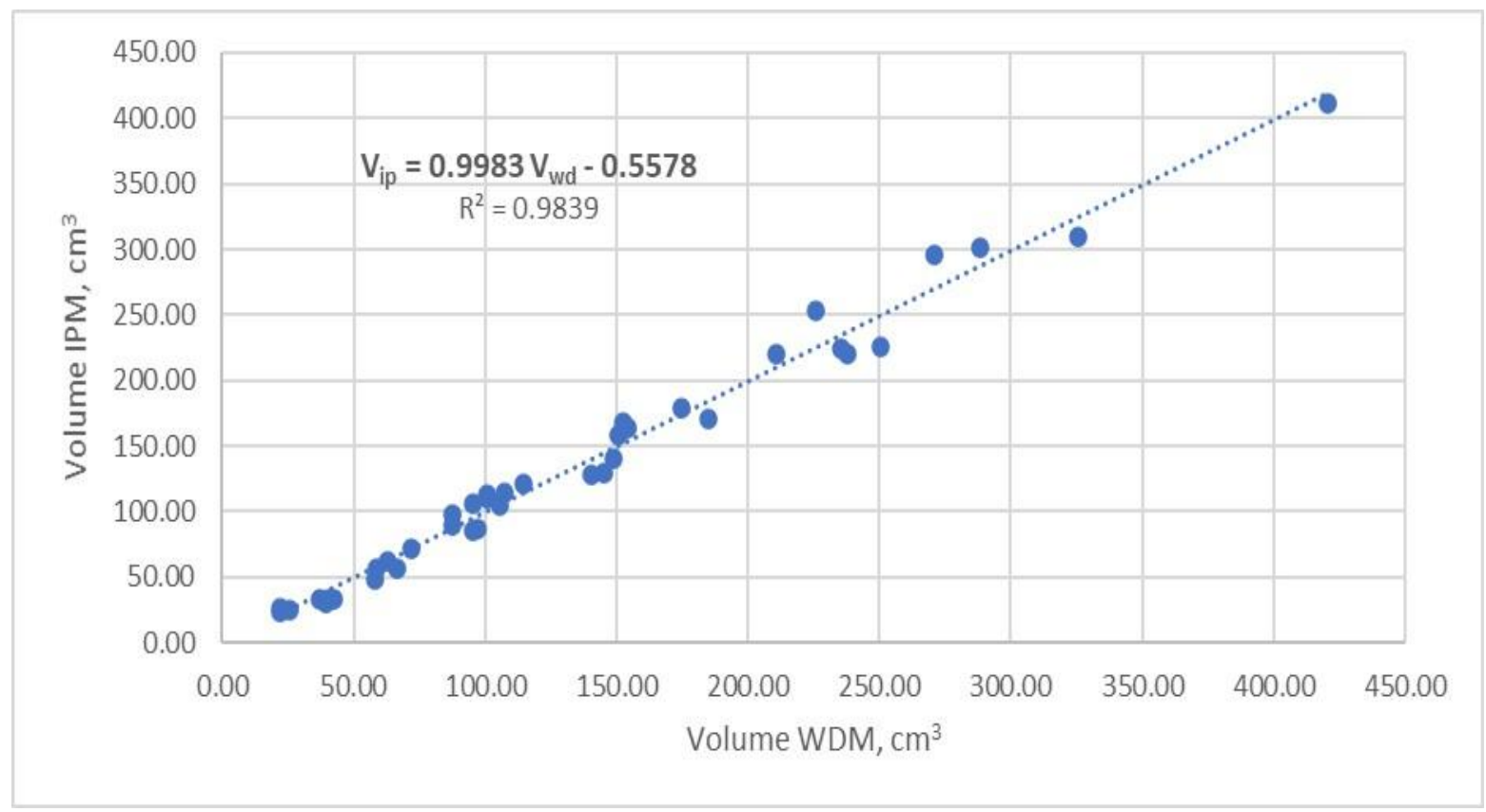

Figure 6: Calibration of volume of orange fruit with image processing (IP) method.

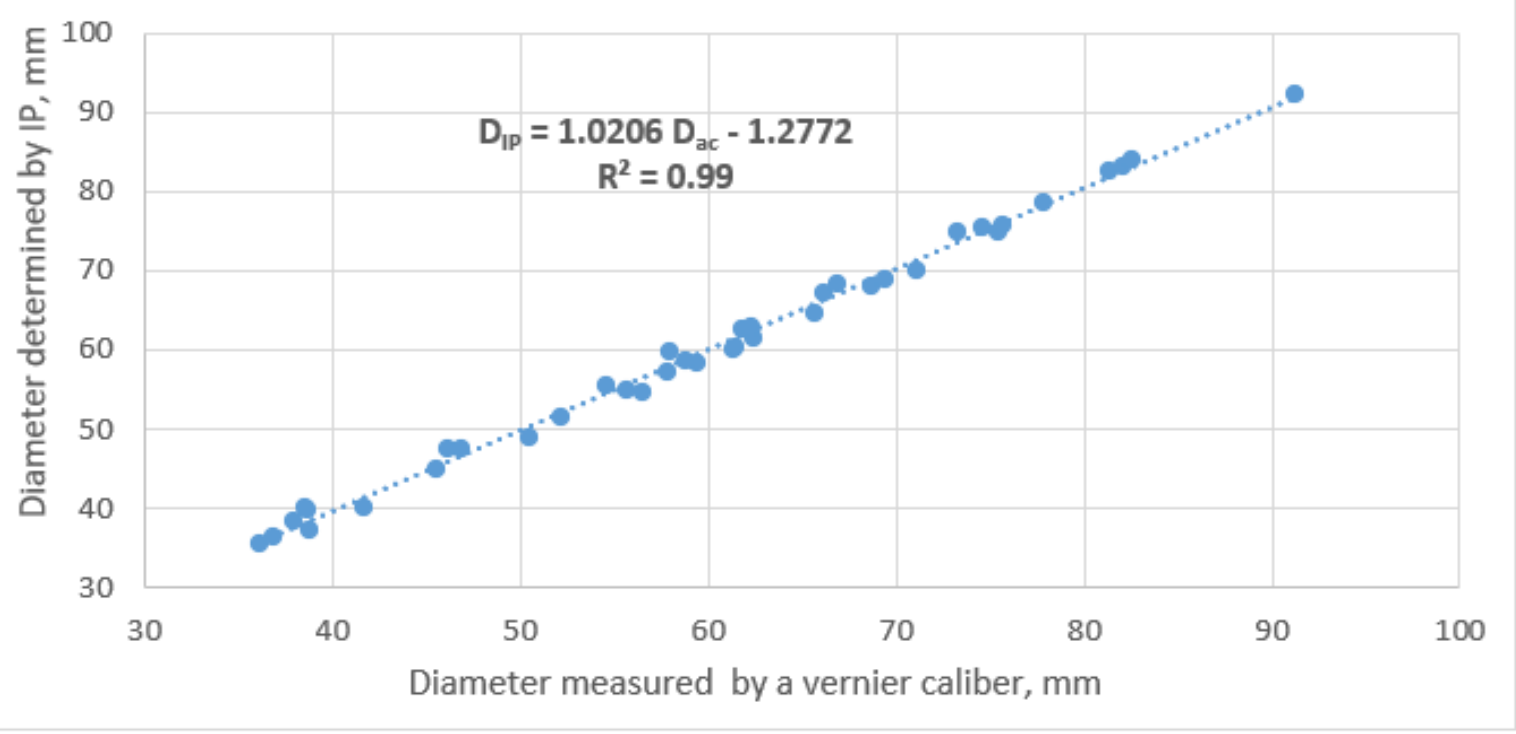

Figure 7: Calibration of diameter of orange fruit with image processing (IP) method 


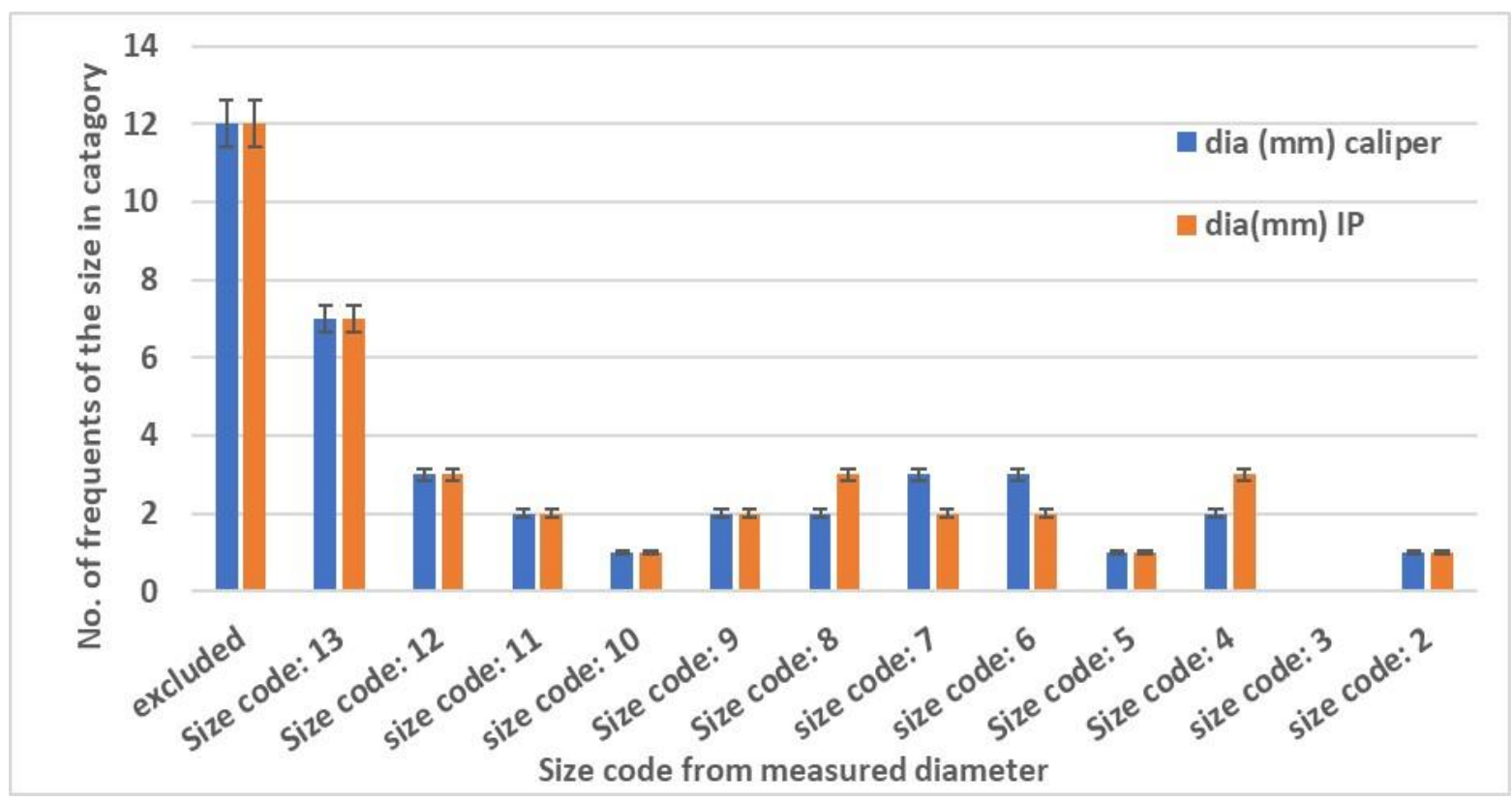

Figure 8: Evaluation of size category for fruits by caliper and IP methods.

\section{CONCLUSION}

The image processing method satisfactorily estimated orange volume and size. Accordingly, image processing provides an accurate, simple, rapid, and noninvasive method to determine orange volume and size, and can be easily implemented in monitoring growth development under various management practices and sorting of orange during post-harvest processing.

\section{REFERENCES}

Abhayawick, L.; J. C. Laguerre; V. Tauzin and A. Duquenoy (2002). Physical properties of Three onion varieties as affected by the moisture content. J. Food Eng. 55(3), 253262.

Akar, R. and C. Aydin (2005). Some physical properties of gumbo fruit varieties. J. Food Eng. 66, 387-393.

Arakeri, M.P. and Lakshmana (2016). Computer vision-based fruit grading system for quality evaluation of tomato in agriculture industry. Procedia Comput. Sci. 79, 426-433.

Aydin, C. and M. Ozcan (2002). some physico-mechanic properties of terebinth (PictaciaterebinthusL.) Fruits. J. Food Eng. 53, 97-101.

Aydin, C. (2003). Physical properties of almond nut and kernel. J. Food Eng. 60, 315-320.

Aydine, C. and M. Ozcan (2007). Determination of nutritional and physical properties of Myrtle (MyrtuscommunisL.) fruit growing wild in Turkey. J. Food Eng. 79, 453-458.

Codex Alimentarius (2005). Standard for oranges: Codex Stan 245-2004. $1^{\circ}$ Amendment. Rome: FAO e WHO, 6 p.

Eissa, A. A.; A. A. Khalik; and A. A. Abdel (2012). Understanding color image processing by machine vision for biological materials. Structure and Function of Food Engineering, pp. 227-274. 
European Commission (2011b).European Commission Regulation (EU) No 543/2011 of 7 June 2011 laying down detailed rules for the application of Council Regulation (EC) No $1234 / 2007$ in respect of the fruit and vegetables and processed fruit and vegetables sectors Regulation No 1121/2008 of 13 November 2008 establishing the standard import values for determining the entry price of certain fruit and vegetables.

Fellegari, R. and H. Navid (2011) Determining the orange volume using image processing. International Conference on Food Engineering and Biotechnology IPCBEE vol.9IACSIT Press, Singapore, pp. 180-184.

Ge, P.; Q. WU and Y. SUN (2007). The Design of Fruit Automated Sorting System. In International Conference on Computer and Computing Technologies in Agriculture (pp. 165-170). Springer, Boston, MA.

Hassan, H.E. (2002). study of sortingand grading operations of Egyptian mature oranges using visible laser. Ph.D. Thesis, National Institute of laser enhanced science Cairo Univ., Egypt.

Kang, S.P.; A. R. East and F. J. Trujillo (2008).Colour Vision System Evaluation of Bicolour Fruit: A case study with 'B74' mango. Postharvest Biology and Technology 49. pp, 7785.

Khoshnam, F.; A. Tabatabaeefar; M. Ghasemi-Varnamkhasti and A. M. Borghei (2007). Mass modeling of pomegranate (PunicagranatumL) fruit with some physical Characteristics. Sci. Hortic. pp. 114, 21-26.

MATLAB (20 - 9). Image processing toolbox help.

Mohsenin, N. N. (1986). Physical Properties of Plant and Animal Materials. Gordon and Breach Science Publishers, New York, NY., pp.94 - 100.

Moreda, G.P.; J. Ortiz-Cañavate; F. J. García-Ramos and M. Ruiz-Altisent (2009). Nondestructive technologies for fruit and vegetable size determination - A review. J.Food Eng. 92 (2), 119-136.

Naik, S.; and B., Patel (2017). Machine vision-based fruit classification and grading-a review. International Journal of Computer Applications, 170(9), 22-34.

Omobuwajo, T.O.; E. A. Akande and L. A. Sanni (1999). Selected physical, mechanical, and Aerodynamic properties of African breadfruit (Treaulia Africana) seeds. J. Food Eng. 40, 241-244.

Papadakis, S.; S. Abdul-Malek; R. E. Kamdem and K. L. Jam (2000). A versatile and Inexpensive technique for measuring color of foods. Food Technol.-Chicago 54, 48-51.

Razmjooy, N.; B.S. Mousavi; F. Soleymani (2012). A realtime mathematical computer method for potato inspection using machine vision. Computer. Math. Appl. 63 (1), 268279. 
Sadegaonkar, V.D. and K.H. Wagh (2015). Automatic Sorting Using Computer Vision \& Image Processing for Improving Apple Quality. International Journal of Innovative Research and Development, 4(1), pp. 543-546.

Sessiz, A.; R. Esgici and S. Kizil (2007). Moisture-dependent physical properties of caper (Capparisssp.) Fruit. J. Food Eng. 79, 1426-1431.

Zhou, L.; V. Chalana and Y. Kim(1998). A PC-based machine vision system for real-time computeraided potato inspection. Int. J. Imaging Syst. Technol. 9(6), 423-433. 


\section{التصنيف التلقائي لثمار البرتقال باستخدام تقتية معالجة الصور في MATLAB \\ محمد أحمد محمود ميهوب' - مبو'}

' مدرس، قسم الهندسة الزر اعية، كلية الزر اعة، جامعة عين شمس، القاهرة، مصر.

الملخص العربي

يطور هذا البحث خوارزمية آلية لتقنية معالجة صور فرز ثمار البرتقال في برنامج

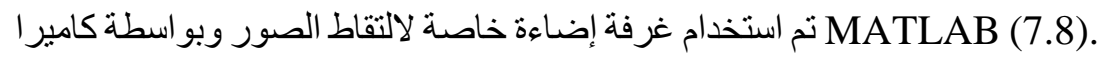

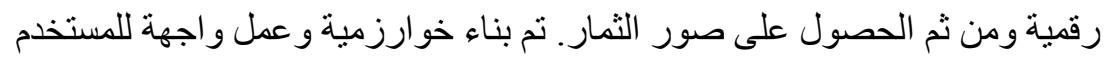

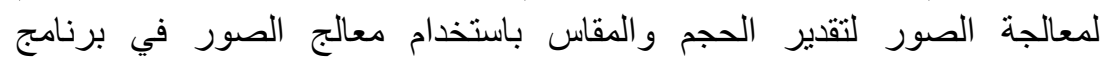

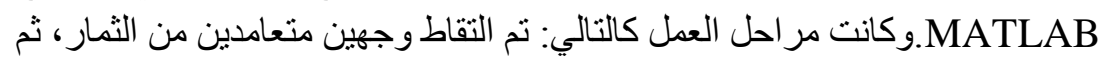
تم معالجة الصور الملتقطة بإخلاء الاضطر اب و والظل منها، وكذللك تم فصل الخهل الخلفية، تبع ذللك مرحلة تصنيف الثمار وفي هذه المرحلة نم تقدير القطر والحجم الحمة الحقيقي

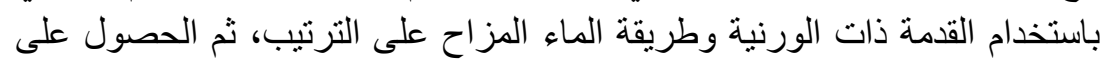

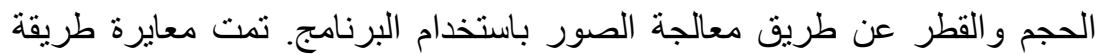

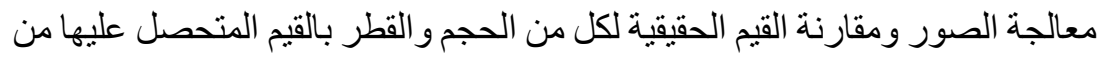

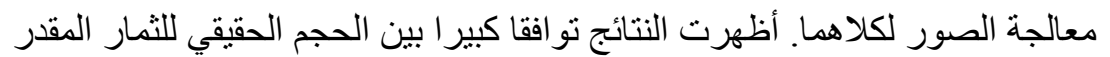

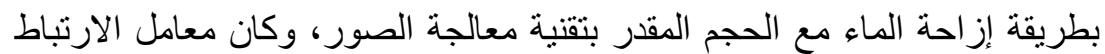

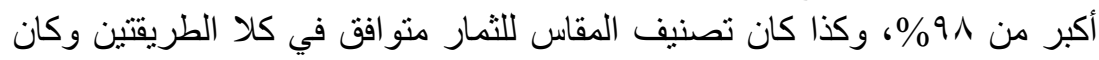

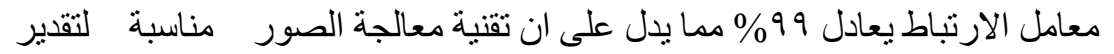

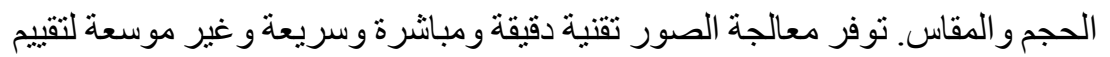

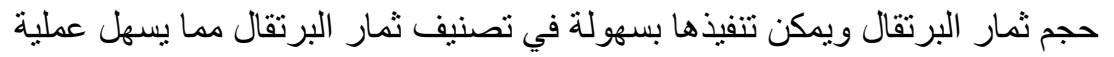

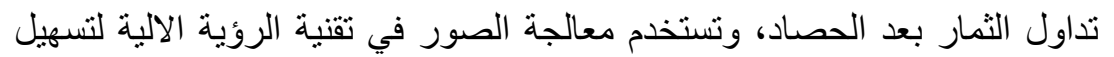
عملية الفرز و التدريج في بيوت التعبئة.

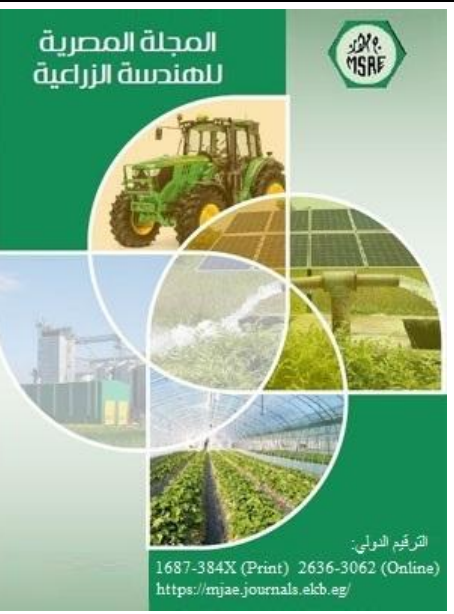

C) المجلة المصرية للهندسة الزراعية

الكلمات المفتاحية:

عملية الفرز، معالجة الصور، الصفاته، المقاس، الحجم، الرؤية الآلية 